\title{
Outro olhar sobre a vigilância sanitária de produtos no Brasil: a legislação de controle sanitário das importaçóes em foco
}

\section{I ${ }^{1}$ Christiane Teixeira dos Santos Delphim, ${ }^{2}$ George Edward Machado Kornis I}

Resumo: Este artigo tem como objeto a regulamentação adotada pelo Brasil no que tange ao controle sanitário da importação de produtos sob vigilância sanitária. O estudo incorporou os aspectos políticos, técnicos, econômicos e institucionais envolvidos no controle das importaçóes. Destaca-se, ainda, a identificação de atores que se mostraram relevantes na formulação e na implantação das normas. Nesta perspectiva, foi realizado estudo singular do conjunto das normatizaçóes publicadas entre 1996 e 2013 editadas desde a antiga Secretaria de Vigilância Sanitária até a Anvisa. Como resultado, foram selecionadas cinco normas para análise, bem como suas alteraçóes posteriores, caracterizando um estudo qualitativo de caráter exploratório, executado com base na análise temática de conteúdo. $\mathrm{O}$ exame desse material permitiu traçar uma trajetória do controle sanitário das importaçóes, possibilitando destacar as condicionantes para as alteraçóes dos regulamentos e os efeitos produzidos por estas. Observou-se que tanto a elaboração quanto os posteriores desdobramentos das normatizaçóes foram influenciados pelas mudanças políticas e econômicas observadas no país e no mundo, sofrendo a determinação de organismos internacionais e de atores intra e extrainstitucionais, que conduziram a restriçóes no controle de produtos importados. O estudo permitiu conhecer melhor a prática da vigilância sanitária, no âmbito da importação.

> Palavras-chave: legislação sanitária; Agência Nacional de Vigilância Sanitária; importação de produtos; regulação em saúde.

\author{
1 Coordenação de Portos, \\ Aeroportos e Fronteiras, \\ Agência Nacional de Vigilância \\ Sanitária. Rio de Janeiro-RJ, Brasil \\ (csteixeira30@hotmail.com). \\ ORCID: 0000-0001-8077-9111 \\ ${ }^{2}$ Instituto de Medicina Social, \\ Universidade do Estado do Río de \\ Janeiro. Rio de Janeiro-RJ, Brasil \\ (gkornis@gmail.com). \\ ORCID: 0000-0002-2322-212X
}

Recebido em: 22/02/2018 Revisado em: 07/08/2018 Aprovado em: 08/10/2018 


\section{Introdução}

Este artigo resulta de uma dissertaçáo de mestrado que teve como objeto de estudo a regulamentaçáo adotada pelo Brasil referente ao controle sanitário da importação de produtos sob vigilância sanitária. Para tal, foi realizado estudo do conjunto das normatizaçóes publicadas entre 1996 e 2013, editadas desde a antiga Secretaria de Vigilância Sanitária (SVS) até a Anvisa. Partiu-se deste objeto para tentar compreender os diferentes contextos sociopolíticos, técnicos, institucionais e econômicos do país que conformaram tais normatizaçóes.

Além disso, representa a possibilidade de estudar uma faceta da regulação que possui vínculos profundos com o modelo de saúde adotado no Brasil. O Sistema Único de Saúde (SUS) tem como um dos pilares a Assistência Farmacêutica (AF), que contempla, dentre outras atividades, a distribuição de medicamentos, em um país que não possui uma indústria farmacêutica robusta capaz de suprir a demanda gerada por este sistema.

As primeiras portarias SVS/MS ( $\mathrm{n}^{\circ}$. 190/1996 e no. 772/1998), que versavam, especificamente, sobre os procedimentos relativos ao controle sanitário dos produtos importados no âmbito da antiga Secretaria de Vigilância Sanitária, foram publicadas na esteira da reforma do Estado, iniciada em 1995, período do primeiro governo Fernando Henrique Cardoso - FHC (1995-1999) (DELPHIM, 2015).

Outras mudanças, ainda no governo FHC, também influenciariam a aprovação das Portarias da SVS citadas como:

(1) publicação da nova Lei de Propriedade Intelectual, em 1996, que iniciou significativo redirecionamento do mercado de medicamentos (BRASIL, 1996a);

(2) agravamento da crise da vigilância sanitária, confirmando a necessidade de profundas mudanças no sistema de regulamentação e controle sanitário do país (PIOVESAN, 2002);

(3) aumento exponencial das importações de produtos farmacêuticos, explicitando a necessidade de maior ação de controle de caráter internacional (MAGALHÂES et al., 2003).

Esse aumento foi impulsionado pela suspensão das licenças e barreiras não tarifárias à importação e revisão das tarifas alfandegárias, executadas no governo Collor (1990-92) (RAMOS, 2008; SALLUM JR., 2011). A agenda da reforma 
orientada para a conformação de uma "administração gerencial" favorecia o debate sobre a criação de uma agência federal com maior autonomia voltada para a regulação sanitária (LUCCHESE, 2001). Assim, o novo modelo político-administrativo do país, que Gonçalves (2013) caracteriza como liberal periférico, conduziu a criação das agências reguladoras.

No final da década de 1990, foi criada a Agência Nacional de Vigilância Sanitária - Anvisa (BRASIL, 1999), com a finalidade institucional de promover a proteção da saúde da população, por intermédio do controle sanitário da produção e da comercialização de produtos e serviços submetidos à vigilância sanitária. No ano seguinte, a Agência Nacional de Saúde Suplementar - ANS, ${ }^{1}$ fazendo com que a saúde no Brasil passasse a ser regulada por duas agências, com atuaçóes em áreas diferentes, mas complementares.

A Anvisa nasceu junto com a formalização do Sistema Nacional de Vigilância Sanitária (SNVS), ${ }^{2}$ assumindo a responsabilidade de coordenação desse sistema. A criação dessa agência fortalece as ações de vigilância sanitária, setor da saúde pública integrante do SUS. E consolida a necessidade de regulação do risco, que foi incorporado ao conceito dado à vigilância sanitária na Lei Orgânica da Saúde (LOS) $n^{\circ}$. 8.080/1990 (BRASIL, 1990). Com a Anvisa, novos regulamentos relativos ao controle sanitário de mercadorias importadas se internalizaram.

Nesse processo de revisão das funçôes do Estado brasileiro e mudanças políticas e econômicas internas, na trilha da reordenação econômica internacional, constatouse que alteraçôes nas regras na liberação dos produtos importados sob controle da vigilância sanitária no país se fizeram frequentes. Frente a esse contexto, questionouse quais seriam as condicionantes para as alteraçôes das normas no âmbito da importação, que resultou neste estudo.

\section{Tipo de estudo e opçóes metodológicas}

Trata-se de estudo qualitativo de caráter exploratório, documental e retrospectivo. A análise começou em 1996-fruto do marco histórico importante gerado pela publicação das Portarias SVS/MS no. 190/1996 (primeira norma específica) e no. 772/1998, ainda no âmbito da antiga Secretaria de Vigilância Sanitária -e foi até 2013 (ano de corte da análise), quando ocorreu a terceira alteração na Resolução da Diretoria Colegiada RDC/Anvisa no 81/2008. 
A pesquisa documental foi realizada em dois momentos distintos, um de coleta de dados a partir dos documentos selecionados, e outro de análise de conteúdo (BARDIN, 2009). Os procedimentos metodológicos da análise de conteúdo utilizados a partir da perspectiva da pesquisa qualitativa incluem: categorização, inferência, descrição e interpretação - que não ocorrem, necessariamente, de forma sequencial (GOMES, 2009).

A análise de conteúdo possibilitou identificar uma trajetória dos regulamentos marcada por três tônicas (ênfase na economia, na regulação sanitária e na simplificação da regulação) que permitiram periodizar a discussão. A definição das tônicas baseou-se nas motivaçóes que permearam as mudanças na legislação. Buscou-se identificar os atores sociais envolvidos na formulação e implantação dos regulamentos, as características da política institucional no momento das alteraçóes e o contexto político e econômico vivido no país.

Foram utilizadas as seguintes fontes:

- Legislação brasileira sobre o controle sanitário, no âmbito da importação, de produtos sujeitos à vigilância sanitária e suas alterações;

- Relatórios de gestão da Anvisa - 1999 a 2013; Relatório de atividades da Anvisa $-2005^{3}$ a 2013;

- Relatório sobre Anvisa da Câmara Americana de Comércio (Amcham) - 2005 a 2012; ${ }^{4}$ Resoluçôes de Mercado Comum do Sul (Mercosul), Organização Mundial do Comércio (OMC) relativas ao controle sanitário internacional;

- Relatório da Organização para a Cooperação e Desenvolvimento Econômico (OCDE);

- Orientaçôes de Serviço da Anvisa;

- Documentos de domínio público, internet, apresentaçóes, outros materiais como gravaçôes (transcrição da oficina de trabalho para orientação sobre a RDC no. 350/2005), livros, artigos científicos, teses, dissertaçóes e matérias jornalísticas dos jornais Folha de S.Paulo (1996 a 2013) e Valor Econômico (2013 e 2014), primordialmente.

A busca nos jornais foi feita utilizando como palavras-chave: "Anvisa", "controle sanitário" e "vigilância sanitária". 


\section{Resultados e Discussão}

\section{Subperíodo pré-Anvisa}

\section{Tônica com ênfase na economia}

No Brasil, na década de 1990, ao mesmo tempo em que se observavam avanços no processo de democratização, enfrentavam-se dificuldades no plano econômico, dada a nova ordem mundial de consolidação do receituário neoliberal (SALLUM JR., 1999; KINZO, 2001). Diante do cenário político, econômico e social vivido no país, da observação ao aumento das importações de produtos vinculados à saúde, dos acordos estabelecidos na OMC e da execução de açóes por demanda ou influência do Mercosul, emergiu a necessidade de regulamentar as questóes relativas à importação de produtos no Brasil.

Em 1995, com o Plano Real já em vigor e as políticas de integração comercial do Mercosul em andamento, a condução da política de importação passou a se subordinar aos objetivos da estabilização de preços e proteção dos setores mais afetados pela abertura da economia. Interesses que exercem pressóes antagônicas, uma vez que o primeiro demanda abertura da economia para as importaçóes, enquanto o segundo baseia-se no oposto. Mas a orientação das políticas comerciais da década de 90, na busca do equilíbrio da economia, foi focada neste paradoxo. (AVERBUG, 1999, p. 47).

A Portaria SVS/MS no. 190, de 4 de dezembro de 1996, foi a primeira regulamentação sanitária que unificou e padronizou regras para a fiscalização e liberação de produtos importados submetidos ao regime de Vigilância Sanitária em terminais alfandegados instalados no território nacional. Mas questionamentos relativos a exigências da norma logo se fizeram presentes, já que para a importação de alimentos, destacava-se a seguinte frase: “Obrigatória a fiscalização sanitária quando do desembaraço aduaneiro sujeito, à análise de controle quando do desembarque no país" (BRASIL, 1996b).

Não havia inovação, em nenhum aspecto, na legislação brasileira, uma vez que o Decreto-Lei no. 986/1969, ${ }^{5}$ que instituiu normas básicas para alimentos, já estabelecia que os alimentos deveriam ser controlados nos portos, aeroportos e fronteiras. O detalhe, conforme análise de Biancarelli (1997) e Lucchese (2001), é que esse decreto não era obedecido com o devido rigor e, naquela ocasião, a SVS queria fazer valer a legislação nacional. E para intensificar as animosidades 
no âmbito do Mercosul, em janeiro de 1997, a SVS publicou outra portaria determinando que os importadores de alimentos fossem licenciados pelo órgão competente de vigilância sanitária da Secretaria de Saúde da unidade federada onde iria se instalar, além da necessidade de envio de amostra para análise laboratorial, antes do embarque da mercadoria no exterior (BRASIL, 1997).

Naquele momento, o Mercosul estava em seu auge em termos de trocas comerciais e o Brasil representava o maior mercado das exportaçôes argentinas (US \$ 1,2 bilhão em alimentos elaborados para o Brasil em 1996). As portarias foram consideradas barreiras não tarifárias, contrárias aos objetivos da integração prevista no Tratado de Assunção, acirrando os conflitos com a Argentina. ${ }^{6}$ Como resultado, esta tentativa de controle da importação de produtos sob vigilância sanitária foi submetida a sucessivas alteraçôes, até sua revogação total em 1998.

A princípio, poder-se-ia dizer que a SVS entrou em rota de colisão com a política de comércio exterior adotada no Brasil, particularmente na consolidação das políticas pactuadas no Mercosul. As decisóes sobre este controle extrapolaram o escopo de atuação do Ministério da Saúde, sendo entáo envolvidos os Ministérios da Fazenda e das Relaçóes Exteriores, em especial o Itamaraty e a Câmara de Comércio Exterior, na arena decisória das açôes (PIOVESAN, 2002).

Mas a decisão da SVS de exigir o cumprimento do Decreto-Lei no. 986/1969, que impactava diretamente sobre a importação de um item (alimentos) "precioso" nas relaçôes comerciais entre o Brasil e a Argentina, teria sido impulsionada pela necessidade de se adotar uma medida de caráter sanitário com finalidades econômicas, já que o Brasil começava a enfrentar deficit em sua balança comercial? Ou tratou-se, realmente, de uma medida de caráter sanitário de cumprimento da legislação até então vigente, de alimentos, num ato isolado da política de comércio exterior que se desenhava no Mercosul?

É preciso assinalar que, nesse período, a Secretaria de Vigilância Sanitária não vivia seus melhores dias; suas açóes foram incorporadas no rol de preocupaçôes do Governo Federal, uma vez que tanto no plano político quanto no social havia uma projeção muito negativa do seu papel. No plano político, pelas denúncias recorrentes de corrupção acarretando sucessivas trocas de dirigentes; e no plano social, pelas denúncias relativas à falta de controle sanitário nos serviços de saúde. Mas o impacto na área econômica e nas relaçôes de comércio exterior gerado pelas publicaçôes dessas portarias, especialmente sobre as negociaçôes no Mercosul, já dava indícios 
de como qualquer tentativa de normatização na área de importação de produtos não seria tarefa fácil e muito menos isenta de interesses.

A portaria seguinte, acerca das regras para importação de produtos sob vigilância sanitária, foi publicada em outubro de 1998, ainda pela antiga SVS. Mas, no período entre 1996 e 1998, a vigilância sanitária foi tomada por uma série de problemas que cada vez mais expunham a sua fragilidade técnica e institucional. Em seguida aos problemas com a Argentina, referentes aos trabalhos de harmonização da regulamentação no Mercosul, ainda em 1996 foram registradas mortes em serviços de saúde, associadas às péssimas condições sanitárias. Os problemas seguiram em 1997 e chegaram ao ápice com as falsificaçōes de medicamentos que explodiram em 1998 (LUCCHESE, 2001, p. 17; PIOVESAN, 2002, p. 44).

Isto posto, não se pode deixar de destacar que, em 1997, iniciou-se um período difícil para a economia brasileira, com crises internacionais, a balança comercial em franco decesso e as sucessivas tentativas do governo de melhorar o quadro geral da economia. O governo, inclusive, tomou uma série de medidas, objetivando a diminuição das importaçôes e, consequentemente, o deficit da balança comercial. Uma das medidas adotadas foi a elevação das alíquotas do imposto de importação de leite em pó e alguns queijos, por exemplo, que muito agradou aos produtores nacionais de leite (NASCIMENTO, 1998; AVERBUG, 1999).

Em 05 de outubro de 1998, foi promulgada a Portaria $n^{\circ} .772$, que aprovou procedimentos relativos à importação de produtos e matérias-primas sujeitos à vigilância sanitária, revogando definitivamente a Portaria no. 190/1996 (BRASIL, 1998). Ao mesmo tempo em que tentou se adequar à normatizaçáo e às regras estabelecidas no Mercosul, a nova portaria apresentou um conteúdo afinado com as políticas de comércio exterior adotadas, ${ }^{7}$ naquele momento no Brasil (SCIARRETTA, 1998). Políticas estas adotadas como resposta às dificuldades enfrentadas na economia brasileira, agravadas por crises internacionais.

Também foi possível identificar que a polêmica questão de cumprimento do Decreto-Lei no. 986/1969, para a importação de alimentos, protagonizada na Portaria no. 190/1996, foi sutilmente contornada. Com efeito, por meio de um "jogo de palavras" ditas e não ditas, a exigência de cumprimento do decreto foi mantida formalmente, mas omitindo-se a necessidade de análise de controle, evitando assim um novo ciclo de embates intra e supranacionais. 
No que diz respeito ao conteúdo, a portaria fez parte do pacote do governo, de medidas restritivas à importação, iniciadas ainda no primeiro semestre de 1998, quando vários produtos agropecuários, farmacêuticos, químicos e alimentícios ficaram submetidos ao regime de licenciamento automático. ${ }^{8}$ Com o estabelecimento dessa "barreira", os produtos argentinos já passaram a ter dificuldades de entrada no país. Diante dos fatos, a Argentina apresentou uma reclamaçáo contra o uso desse mecanismo durante a $18^{\text {a }}$ Reunião do Conselho Mercado Comum realizado em abril de 1998 (INTAL, 1999).

Com a ediçâoo da Portaria no ${ }^{\circ}$ 772/1998, a relaçâo entre os dois países ficou ainda mais estremecida, pois acrescentaram-se ao escopo de alimentos sujeitos à vigilância sanitária e, consequentemente, ao licenciamento de importação, todos os produtos alimentícios de origem animal como ovos, carnes, leites, peixes, além de frutas, verduras e legumes frescos (BRASIL, 1998). Esses itens representavam os principais alimentos exportados da Argentina para o Brasil em 1996 (BERTOLOTTO, 1997).

O governo argentino e as empresas exportadoras desse país foram enfáticos e taxaram a incorporação desses produtos ao licenciamento não automático pela Portaria no. 772/1998 como uma barreira não tarifária. A Câmara de Exportadores da República Argentina (CERA) também reclamava que a liberação de um licenciamento de importação (LI) poderia demorar mais de 30 dias (VIGEVANI et al., 2002).

As situaçôes aqui descritas - associadas à quebra do compromisso firmado por meio do Decreto no. 2.697/1998, que dispôs sobre a execução do acordo quadro de superação de barreiras técnicas ao comércio entre Brasil, Argentina, Bolívia, Chile, Colômbia, Equador, México, Paraguai, Peru e Venezuela — contribuíram de maneira decisiva para que fosse acionado o sistema de solução de controvérsias do Mercosul em 1999, na tentativa de solucionar os entraves comerciais entre Brasil e Argentina, gerando sucessivas deliberaçôes, que culminaram na decisão do tribunal, em 2002, de que o Brasil havia descumprido os acordos firmados (MERCOSUL, 2002).

Após análise das políticas econômicas adotadas no Brasil, particularmente no período compreendido entre 1994 e 1998, combinadas à publicaçáo das Portarias nos 190/1996 e 772/1998, observou-se que as decisóes sobre esse controle extrapolaram o campo das exigências sanitárias. Mesmo que o controle sanitário tenha sido legítimo, ao fim e ao todo, mesmo que tenham sido legítimas do ponto de vista do controle sanitário, as Portarias no. 190/1996 e 772/1998 foram 
caracterizadas, por diferentes atores do cenário político, econômico e social, como instrumentos de barreiras não tarifárias.

Entretanto, independentemente de ser a melhor estratégia econômica ou não, ressalta-se que, ao contrário do que dizem alguns autores, esta não é uma política adotada pelos latino-americanos. ${ }^{9}$ As políticas protecionistas adotadas pelo Brasil não diferem das que foram adotadas pelos países atualmente desenvolvidos, quando no período de catch-up. Chang (2002) destaca que o intervencionismo foi uma prática adotada pelos países desenvolvidos visando a alcançar o desenvolvimento econômico.

Quanto à diferença dos desfechos das portarias, a crise econômica que abatia o Brasil e o mundo ${ }^{10}$ dificilmente conduziria a outra medida que não fosse a manutenção das regras impostas pela Portaria SVS/MS no. 772/1998, a despeito das pressôes externas quanto à sua ilegitimidade. Cumpre também destacar que, somando tudo isto, havia um modelo de vigilância sanitária no Brasil que se ressentia de sua própria fragilidade e o temor do agravamento das condiçôes insuficientes de controle.

\section{Subperíodo pós-Anvisa}

\section{Tônica com ênfase na regulaçâo sanitária}

O regulamento que substituiu a Portaria SVS/MS no 772/1998 foi publicado no âmbito da Anvisa na forma de resolução em 2003 (RDC no 01/2003). Os anos compreendidos entre a publicação da Portaria SVS/MS no 772/1998 e a RDC no 01/2003 foram justamente o período do segundo mandato do presidente FHC, que logo teve que permitir a desvalorizaçáo do real em face ao dólar (FAUSTO, 2013).

No plano da vigilância sanitária, a medida provisória que havia criado a Agência Nacional de Vigilância Sanitária, no final de 1998, tornou-se a Lei no. 9.782, de 26 de janeiro de 1999. Esta mesma lei definiu o Sistema Nacional de Vigilância Sanitária, assim como modificou o polêmico artigo 57 do Decreto-Lei no. 986/1969, tão explorado nas normas anteriores de controle sanitário das importaçóes. $\mathrm{O}$ referido artigo determinava a obrigatoriedade da análise de controle nas importaçôes de alimentos e materiais que entrassem em contato com eles no momento de seu desembarque no país. A obrigatoriedade da referida análise ficou a critério da autoridade sanitária, a partir dessa lei (BRASIL, 1999). Nesse momento, a Anvisa fechou um ciclo de disputas e conflitos que se amparavam no argumento do legítimo cumprimento do referido decreto. 
Mesmo com a criação da Anvisa, houve uma espécie de inércia institucional para a aprovaçáo de uma nova norma sobre controle sanitário de produtos importados até 2002. Ano em que, elementos facilitadores intra e extra-institucionais permitiram mudar o curso da importação de produtos sob vigilância sanitária, com a publicação do novo regulamento. Conforme descreve Immergut (1996), ao abordar os determinantes das decisóes políticas, alçou-se na área de portos, aeroportos e fronteiras uma "janela de oportunidade".

Na esfera política, esta RDC foi assinada em dezembro de 2002, momento de mudança no panorama político, com a eleição do presidente Lula e a formação de uma equipe de transição ${ }^{11}$ que trabalhou juntamente com a equipe do governo FHC. Durante o trabalho dessa equipe, foi questionado o papel das agências reguladoras no governo FHC e os encaminhamentos que seriam dados a esses órgãos reguladores no governo Lula. Para tal, a equipe de transição fez um mapeamento dos principais problemas que estavam sendo deixados pelo governo FHC para o governo Lula, na tentativa de entender que problemas enfrentariam junto às agências reguladoras (COSTA e ANDRADE, 2003).

$\mathrm{Na}$ esfera sanitária, o período que antecedeu à publicação da norma foi marcado pela incidência, na Europa, da encefalopatia espongiforme bovina (EEB), popularmente conhecida como "doença da vaca louca", juntamente com o foco de febre aftosa, em 2002, que contribuiriam para mudar a dinâmica do consumo, da produção e do comércio internacional de produtos, provocando, naturalmente, restriçôes internacionais de caráter sanitário (SILVA et al., 2008). Parece razoável deduzir, assim, que a publicaçáo da RDC nº. 01, em dezembro de 2002, foi motivada pela necessidade de dar respostas sanitárias e técnicas à nova equipe política sobre o papel das agências. A aprovação de um novo regulamento daria o suporte que o governo FHC precisava para contornar as exigências políticas e sanitárias latentes.

Faz-se também necessário assinalar alguns fatores que, embora possam não ter sido decisivos, provavelmente contribuíram para a incorporação do controle de mercadorias importadas na agenda de decisão da Anvisa em 2003, como:

- o incremento, tanto no número como na etapa de fabricação (a granel, semielaborado, acabado, matéria-prima) da importação de produtos sob vigilância sanitária;

- a complexidade de açôes assumidas pela Anvisa, que demandaram outras finalidades de importação não contempladas na norma que estava vigente; 
- a necessidade de adequação do Brasil às exigências internacionais na área, particularmente os acordos Mercosul que deveriam ser cumpridos;

- e a própria demanda do setor regulado, para que uma norma que respondesse às demandas reais entrasse em vigor.

A RDC no. 01, de 10 de janeiro de 2003, inaugurou um novo "formato" de regulamento sanitário para a importação de produtos sob vigilância sanitária, apresentando a robustez técnica compatível ao escopo de atuação assumido pela Anvisa. Com efeito, foi a partir da publicação da RDC no ${ }^{\circ}$. 01/2003 que a agência participou de forma mais efetiva no processo de importação (BRASIL, 2003).

A despeito da demora na publicaçâo de um novo regulamento técnico para mercadorias importadas sob vigilância sanitária, esse regulamento procurou se adequar às normas intra e interinstitucionais com interface no âmbito da importação. Além disso, permitia vislumbrar que o monitoramento de produtos sob vigilância sanitária - que envolve toda a cadeia de distribuição, desde a saída do exterior até a chegada ao seu local de destino e posterior envio ao consumo- deve ser cuidadosamente avaliado com base nas boas práticas de armazenagem, transporte e quaisquer outros serviços pertinentes a essa cadeia.

Diante das exigências do setor regulado e da necessidade de rever os procedimentos de controle e fiscalização de bens e produtos procedentes do exterior, foi publicada a RDC no. 350, em 28 de dezembro de 2005, revogando a RDC no. 01/2003. Em linhas gerais, a nova RDC permitiu que as intervençôes sanitárias, na maior parte das mercadorias, só fossem realizadas no momento em que a carga chegasse ao território nacional. Dessa forma, os importadores ficaram desobrigados de requerer, junto à Anvisa, a autorização de embarque no exterior.

Nesse momento, a discussão e as críticas às agências reguladoras não estavam mais na pauta do governo. Primeiramente, porque o foco era a crise do mensalão, ${ }^{12}$ e depois porque, após dois anos de mandato, o governo já conseguia formar uma coalizão de apoio por dentro das agências reguladoras conforme reportagens da Folha de São Paulo. ${ }^{13}$ Em síntese, arenas, atores, regras do jogo e cenário regulatório já tinham algum controle do governo. As diretorias das agências começavam a ser renovadas e o governo já não estava mais "fora" das agências, mas "dentro" delas por meio dos seus aliados. 
A proposta inicial da RDC no. 350/2005 foi aprimorar os procedimentos e incorporar o máximo de elementos envolvidos na etapa da importaçáo de produtos sob vigilância sanitária. Entretanto, pelas alteraçóes que comprometeram a análise e por conter alguns textos equivocados e confusos, a resolução foi alvo de muita polêmica no setor regulado e até mesmo por atores internos ${ }^{14}$ da Anvisa.

Dentro do contexto dos atores envolvidos, entrevistas realizadas por Sebastiáo (2007, p. 51, 76) expuseram que o setor regulado reconhecia a necessidade de aperfeiçoar as competências institucionais exercidas pela Anvisa, para criar um ambiente adequado à inserção do país e, consequentemente, de suas atividades de comércio exterior, no mercado globalizado, mas ao mesmo tempo desejava que tal inserção fosse feita sem afetar seus investimentos. Um outro entrevistado chegou a dizer que as empresas querem que seus produtos cheguem logo a suas fábricas e, se o processo demora, há duas maneiras de se resolver o problema: discutir com o órgão algo que seja mais eficiente ou iniciar uma discussáo sobre a redução do papel do regulador, classificando-o como burocrático (SEBASTIÃO, 2007, p. 117).

\section{Tônica com ênfase na simplificação da regulação}

Em novembro de 2008, a RDC no. 350/2005 foi revogada pela RDC no. 81/2008. A publicaçáo da nova norma aconteceu num momento de muitas mudanças no Brasil e no mundo. A crise financeira que se estabeleceu no segundo semestre de 2008 foi um divisor de águas para a economia mundial. No Brasil, buscava-se intensificar a política industrial, por meio das Parcerias para o Desenvolvimento Produtivo (PDPs), que também tiveram seu curso alterado pela crise. $\mathrm{Na}$ Anvisa, havia a intensificação do programa de melhoria da regulação, com a publicação do Guia de Boas Práticas Regulatórias e das diretrizes para a avaliação do impacto regulatório.

Evidencia-se que a linha adotada pela Anvisa na área de importação de produtos ficou ancorada não mais em práticas sanitárias, mas nas práticas de comércio exterior que o Brasil adotou a partir de 2007, com a resoluçáo no. 70/2007 da Câmara de Comércio Exterior (Camex), que solicitou aos órgãos anuentes que racionalizassem e simplificassem procedimentos para facilitar as operaçôes de comércio exterior. A mudança do perfil profissional do gerente responsável pela área de importação e do discurso da área — com ênfase nas palavras "simplificar", "agilizar" e "reduzir" — legitimou as açôes assumidas pela gerência no âmbito da importação de produtos (DELPHIM, 2015). 
A lógica da "melhor regulação" em pauta na agenda regulatória internacional também teve seu papel nas mudanças do curso da importação. Para alguns autores, conforme descrito por Silva (2013), a agenda de "melhor regulação" é uma simples adequação da reforma regulatória do final dos anos 1980, determinada a reduzir a influência e os impactos da regulação estatal sobre o modelo de investimentos e o comércio internacional. As recomendaçôes, da OCDE, da OMC e do próprio Mercosul, corroboram que a "melhor regulação" é a que envolve simplificação e agilizaçáo de procedimentos para que se favoreça o desenvolvimento econômico.

Nesse momento, é imperioso citar Chang (2002), que é enfático ao afirmar que se os países desenvolvidos tivessem mesmo adotado as políticas que recomendam aos países em desenvolvimento, não seriam o que são hoje. Muitos deles, ao longo de sua trajetória de desenvolvimento, recorreram a políticas comerciais e industriais protecionistas, atualmente consideradas políticas "ruins". Ou seja, os países desenvolvidos estariam "chutando a escada" para que os países em desenvolvimento não consigam seguir os mesmos caminhos trilhados por eles para se desenvolver.

Por outro lado, extrapolando para a aproximação entre o processo de importação e a assistência farmacêutica, as simplificaçôes na importação poderiam ser interpretadas como garantia de acesso, e um dos pilares da AF e do SUS estaria sendo contemplado. Mas quando elas ocorrem no mesmo momento em que estão sendo desenvolvidas políticas de estímulo à indústria nacional, incluindo o complexo industrial da saúde, essas açôes parecem no mínimo controversas. $\mathrm{Na}$ verdade, as próprias políticas estabelecidas pelo governo têm finalidades paradoxais: estabelecem açôes de facilitação de comércio exterior, incluindo as importaçôes, concomitantemente aos programas de estímulo à indústria nacional. E mesmo o acesso facilitado pela flexibilização das importaçôes pode ser comprometido pela qualidade do produto que está sendo disponibilizado.

Taveira (2013) descreve em seu estudo que o Brasil ainda mantém uma situação de dependência externa na área farmacêutica, o que conduz à importação de boa parte dos medicamentos aqui consumidos. A questão é que esses produtos são oriundos de diversas regióes do mundo, o que naturalmente gera uma variação na sua qualidade. Por isso, as normas relacionadas à importação possuem papel fundamental para a manutenção da qualidade dos produtos, estabelecendo regras a serem seguidas pelas empresas importadoras, com o propósito de minimizar o risco sanitário proporcionado por essa prática. Assumindo esse entendimento 
sobre os riscos associados a essas alteraçôes normativas, toma-se como base para discussão o conceito de risco sanitário como a probabilidade de que os produtos e serviços têm de causar efeitos prejudiciais à saúde das pessoas e das coletividades (SILVA; LANA, 2014).

Não obstante a questão do risco sanitário que se avulta cada vez mais, a Anvisa continuou a estampar as páginas dos noticiários com seus cargos sendo disputados e fatiados entre partidos políticos, ${ }^{15}$ relações de conflito de interesses, além das acusaçôes de corrupção contra dirigentes da agência, envolvendo esquema de venda de favores a empresas privadas (VEJA, 2012a, 2012b; BRASIL, 2013). Portanto, a Anvisa também vive sob os riscos da captura do poder político definido por Marques Neto apud Martins (2010), como a subordinação da atividade regulatória aos interesses políticos via coalizão partidária.

O autor continua sua análise enfatizando que essa captura é muito perniciosa, pois fragiliza a legitimidade da agência frente ao setor regulado, à população e até mesmo internamente entre seus pares. Não se pode perder de vista que a Anvisa foi criada para ser autônoma e independente. Quando o governo contingencia recursos e divide a direçáo da agência entre partidos da sua base aliada conforme seus interesses políticos e não em premissas técnicas, age na contramão dos princípios fundamentais da agência.

Em suma, após a análise das normas no período estudado, 1996 a 2013, depreendese que a regulação e a estruturação do sistema regulatório são extremamente complexas e fortemente influenciadas por variáveis políticas, econômicas e sociais. Se por um lado existe a pressão do setor regulado sobre a agência por menos regulação; por outro, há grupos de representação da sociedade que ensejam mais regulação, em busca de proteção, direitos e garantias relacionados à oferta, segurança e qualidade de bens, produtos e serviços. Diante deste mundo contemporâneo globalizado, estruturouse em solo brasileiro um padrão de regulação sanitária que absorveu os matizes do modelo internacional de regulamentação, incluindo ou excluindo o mercado, com maior ou menor espaço às políticas públicas de controle deste mercado.

Sobre o tema, Santos e Silveira (2008) destacam que, na medida em que, num mundo globalizado, o mercado se torna tirano e o Estado, impotente, cada empresa busca satisfazer-se nos lugares onde as respostas a seus anseios parece mais adequada. Tal demanda é imprevisível e o território passa a ter, nas áreas atingidas por esse tipo de relação, uma dinâmica praticamente incontrolável no próprio lugar em que 
se exerce e que é também alienada, já que não precisa ter correspondência com os interesses da sociedade local ou nacional.

\section{Considerações finais}

Concluindo, a formulação e execução das políticas regulatórias, no âmbito da importação de produtos sob vigilância sanitária, não é um processo estático, pois, diante de um mundo tão globalizado, sofre variaçôes de acordo com as mudanças políticas, econômicas e sociais observadas no país e no mundo, ultrapassando os limites institucionais.

Em 2017, uma nova revisão da RDC no 81/2008 esteve em curso e, mais uma vez, o discurso da necessidade da revisão, proveniente tanto do setor regulado quanto da diretoria colegiada da Anvisa, envolvia as palavras simplificar e desburocratizar. Tal processo foi concluído em janeiro de 2018 com a publicação da RDC no 208/2018, que dispóe sobre a simplificação de procedimentos para a importação de produtos sujeitos à Vigilância Sanitária.

Como elementos complicadores para a harmonização das normas com a missão da Anvisa, observaram-se progressivo loteamento dos cargos de diretores da agência, sucessivas tentativas de esvaziamento da mesma e a disputa para que as suas açóes estejam afinadas às políticas de governo, e não as de Estado.

As agências e seus cargos estão colocados entre os temas da ordem do dia do Executivo e do Legislativo, ora disputando cargos, ora com tentativas de supressão das agências reguladoras. Configuram-se um distanciamento progressivo dos propósitos originalmente postos para funcionalidade plena dessas agências e o quadro atual de disputa política por cargos. Uma possível estratégia de minimizar a captura política destes diretores seria a eliminação da recondução ao cargo, na expectativa de que suas decisóes não visassem à manutenção do cargo.

Diante desse quadro, uma mudança de padrão parece necessária à Anvisa, como parte integrante de um sistema nacional e responsável pelas açóes de controle sanitário de produtos importados. A norma em execução deve sofrer o mínimo de interferências de qual ordem for, devendo ser atualizada e reformulada na busca de um controle sanitário que maximize benefícios à população, e o SUS deve ser seu maior referencial. A inserção do SUS nesse contexto se deve à ausência de uma política industrial nacional robusta que dê sustentação a suas diretrizes. 
O Brasil tem uma estrutura vulnerável à importação de princípios ativos, insumos e produtos farmacêuticos acabados, o que dificulta a manutenção do atual modelo de sistema de saúde com assistência farmacêutica universal. E dependente, portanto, da regulaçáo sanitária para a garantia da qualidade do produto importado, principalmente considerando o risco sanitário inerente ao tráfego internacional de mercadorias sob vigilância sanitária.

A atuação da Anvisa, portanto, sendo fiel a sua missão, valores e finalidade institucional, será sempre fundamental para a garantia da credibilidade da agência reguladora, mas sobretudo para a legitimação de sua autoridade como instituição capaz de proteger e promover a saúde da população por meio do controle sanitário de produtos importados sujeitos à vigilância sanitária. ${ }^{16}$

\section{Referências}

ABRUCIO, F. L. Os barōes da federação: os governadores e a redemocratizaçâoo brasileira. São Paulo: Hucitec, 1998. 253 p.

AVERBUG, A. Abertura e integração comercial brasileira na década de 90 . In: GIAMBIAGI, F.; MOREIRA, M. M. (Org.). A economia brasileira nos anos 90. Rio de Janeiro : Banco Nacional de Desenvolvimento Econômico e Social, 1999. p. 43-82. Disponível em: <https://web.bndes. gov.br/bib/jspui/handle/1408/12695>. Acesso em: 20 ago. 2014.

BARDIN, L. Análise de conteúdo. Lisboa: Ediçóes 70, 2009, 223 p.

BERTOLOTTO, R. Argentinos criticam controle sanitário. Folha de São Paulo, São Paulo, 25 fev. 1997. Dinheiro, p. 7.

BIANCARELLI, A. Alimento causa controvérsia entre países. Folha de São Paulo, São Paulo, 21 fev. 1997. Dinheiro, p. 8.

BRASIL. Presidência da República. Decreto-Lei no 986, de 21 de outubro de 1969. Regula direitos e obrigaçôes relativos à propriedade industrial. Diário Oficial da União; Poder Executivo, Brasília, DF. Disponível em:<http://www.planalto.gov.br/ccivil_03/decreto-lei/Del0986.htm>. Acesso em: 22 ago. 2014.

Presidência da República. Lei no 8.080, de 19 de setembro de 1990. Dispóe sobre as condiçōes para a promoção, proteção e recuperação da saúde, a organizaçấo e o funcionamento dos serviços correspondentes e dá outras providências. Diário Oficial da União; Poder Executivo, Brasília, DF, Seção 1, Edição no 182, 20 set. 1990, p. 1.

. Presidência da República. Lei no 9.279 de 14 de maio de 1996. Regula direitos e obrigaçōes relativos à propriedade industrial. Diário Oficial da União; Poder Executivo, Brasília, DF, Seção 1, p. 8.353, 15 maio 1996 . 
. Ministério da Saúde. Secretaria de Vigilância Sanitária. Portaria no . 190, de 04 de dezembro de 1996. Aprova relação das categorias de produtos importados, submetidos ao regime de vigilância sanitária prévia e expressa manifestação favor favorável do Ministério da Saúde e ao desembaraço da carga nível de terminais alfandegados. Diário Oficial da União; Poder Executivo, Brasília, DF, Seção 1, Edição no 236, p. 72, 05 dez. 1996 b.

.Ministério da Saúde. Secretaria de Vigilância Sanitária. Portaria no . 09, de 14 de janeiro de 1997. Determina que a empresa importadora de alimentos, aditivos alimentares e de substâncias empregadas na produção de artigos, equipamentos e utensílios destinados a entrar em contato com alimentos, sejam licenciadas pelo órgão competente de Vigilância Sanitária da Secretaria de Saúde da Unidade Federada, onde a mesma irá se instalar. Diário Oficial da União; Poder Executivo, Brasília, DF, Seção 1, p. 766, 14 jan 1997.

Ministério da Saúde. Secretaria de Vigilância Sanitária. Portaria nº. 772, de 02 de outubro de 1998. Aprova os procedimentos a serem adotados nas importaçóes dos produtos e matérias-primas sujeitos a controle sanitário previstos no Anexo I desta Portaria. Diário Oficial da União; Poder Executivo, Brasília, DF, Seção 1, Edição no 190, p. 5, 05 out 1998.

. Congresso Nacional. Lei no. 9.782, de 26 de janeiro de 1999. Define como Sistema Nacional de Vigilância Sanitária, cria a Agência Nacional de Vigilância Sanitária, e dá outras providências. Diário Oficial da União; Poder Executivo, Brasília, DF, Seção 1, Edição no 18, p. 21, 27 jan. 1999.

. Agência Nacional de Vigilância Sanitária (Anvisa). Resolução RDC nº. 01, de 06 de dezembro de 2002. Aprova, conforme Anexo, o Regulamento Técnico para fins de vigilância sanitária de mercadorias importadas. Diário Oficial da União; Poder Executivo, Brasília, DF, Seção 1, Edição no 7, p. 36, 09 jan. 2003.

. Senado Federal. PMDB e PT travam batalha por cargos na Anvisa. 2013. Disponível em: <http://www.senado.gov.br/noticias/senadonamidia/default.asp>. Acesso em: 15 nov. 2014.

CHANG, H.-J. Chutando a escada: a estratégia do desenvolvimento em perspectiva histórica. São Paulo: Unesp, 2002. 272p.

COSTA, C. C.; ANDRADE, H. Governo de Transição FHC-LULA: constituição, funcionamento e resultados dos trabalhos realizados pela equipe do governo de transição FHC-Lula. Rio de Janeiro: Observatório Universitário, 2003. (Documento de Trabalho no 10; Série Estudos de Políticas Públicas).

DELPHIM, C. S. T. Outro olhar sobre a vigilância sanitária de produtos no Brasil: a legislação de controle sanitário das importações - da Secretaria à Anvisa - em foco. Dissertação (Mestrado em Saúde Coletiva) - Instituto de Medicina Social, Universidade do Estado do Rio de Janeiro, Rio de Janeiro 2015. $244 \mathrm{f}$

FAUSTO, B. História do Brasil. 14. ed. São Paulo: Edusp, 2013. 677p. 
FUNDAÇÃO OSWALDO CRUZ. Importação passo a passo. Disponível em: <http://www. dirad.fiocruz.br/?q=node/143>. Acesso em: 16 ago. 2014.

GOMES, R. Análise e interpretação de dados de pesquisa qualitativa. In: DESLANDES, S. F.; GOMES, R.; MINAYO, M. C. S. (Orgs.). Pesquisa social. Teoria, método e criatividade. 28. ed. Rio de Janeiro: Vozes, 2009. p. 79-108.

GONÇALVES, R. Desenvolvimento às avessas. Verdade, má-fé e ilusão no atual modelo brasileiro de desenvolvimento. Rio de Janeiro: LTC, 2013. 182 p.

IMMERGUT, E. M. As regras do jogo: a lógica da política de saúde na França, na Suíça e na Suécia. Revista Brasileira de Ciências Sociais. São Paulo, v. 30, n. 11, p. 139-165, 1996.

INSTITUTO PARA INTEGRAÇÃO DA AMÉRICA LATINA E DO CARIBE (INTAL). Informe Mercosul no 5. Buenos Aires: BID-INTAL, 1998-1999.

KINZO, M. D. G. A democratização brasileira: um balanço do processo político desde a transição. São Paulo em Perspectiva. São Paulo, v. 15, n. 4, p. 3-12, out-dez, 2001.

LUCCHESE, G. Globalização e regulação sanitária: os rumos da vigilância no Brasil. Tese (Doutorado em Saúde Pública) - Escola Nacional de Saúde Pública, Fundação Oswaldo Cruz, Rio de Janeiro, 2001. 239 p.

MAGALHÃES, L. C. G. et al. Tendências da balança de comércio exterior da indústria farmacêutica brasileira: evolução das importaçôes e exportações de farmoquímicos e medicamentos na década de 1990. Planejamento e políticas públicas, v. 26, p. 35-65, jun-dez. 2003.

MARTINS, A. S. Agências reguladoras e os riscos da captura pelos entes regulados: estudo comparativo entre o direito regulatório norte-americano e o brasileiro. Dissertação (Mestrado em Direito Internacional Econômico) - Universidade Católica de Brasília, Brasília, 2010. 108 p.

MERCOSUl. Laudo Arbitral do Tribunal Arbitral "ad hoc"do Mercosul. Assunção, 2002. Disponível em: <http://www.tprmercosur.org/pt/docum/laudos/bras/Laudo_br_07_pt_ Obstac_ingreso_prod_fitosanitarios.pdf>. Acesso em: 25 jan. 2015.

NASCIMENTO, S. Governo contém a importação de leite. Folha de São Paulo, São Paulo, 13 out. 1998. Agrofolha, p. 1.

PIOVESAN, M. F. A construção politica da Agência Nacional de Vigilância Sanitária. Dissertação (Mestrado em Saúde Pública) - Escola Nacional de Saúde Pública, Fundação Oswaldo Cruz, Rio de Janeiro, 2002. 102p.

RAMOS, G. C. C. Comércio internacional, política comercial brasileira e a atuação da câmara de comércio exterior (Camex) na condução das políticas para o setor. Dissertação (Mestrado em Administração Pública) - Escola Brasileira de Administração Pública e de Empresas, Fundação Getúlio Vargas, Rio de Janeiro, 2008, 312p. 
SALLUM JR, B. O Brasil sob Cardoso: neoliberalismo e desenvolvimentismo. Tempo Social. Rio de Janeiro, v. 11, n. 2, p. 23-47, 1999.

. Governo Collor: o reformismo liberal e a nova orientação da política externa brasileira. Dados, Rio de Janeiro, v. 54, n. 2, p. 259-288, 2011.

SANTOS, M.; SILVEIRA, M. L. O Brasil: território e sociedade no início do século XXI. 11ed. São Paulo: Record, 2008. 473 p.

SCIARRETTA, T. Medidas tentam contem importação. Folha de São Paulo, São Paulo, 23 set. 1998. Dinheiro, p. 4.

SEBASTIÃO, P. C. A. O controle sanitário da importação de substâncias psicotrópicas no Brasil. Dissertação (Mestrado Profissional em Saúde Pública) - Instituto de Saúde Pública, Universidade Federal da Bahia, Salvador, 2007. 153 p.

SILVA, A. V. F. G; LANA, F. C. F. Significando o risco sanitário: modos de atuação sobre o risco na vigilância sanitária. Revista visa em debate, Rio de Janeiro, v. 2, n. 2, p. 17-26 , 2014.

SILVA, G. H. T. Performance Regulatória: uma análise do Programa de Melhoria do Processo de Regulamentação da Anvisa no contexto da atual Agenda de Reforma Regulatória do Brasil. Dissertação (Mestrado Profissional em Desenvolvimento e Políticas Públicas) - Fundação Oswaldo Cruz, Escola Nacional de Saúde Pública, Brasília, 2013. 294 p.

SILVA, L. G.; MARION FILHO, P. J.; CAMPOS, I. A dinâmica das exportaçóes brasileiras de carne bovina (1994-2005). Revista de Estudos Sociais, Mato Grosso, v. 19, n. 1, p. 23-49, 2008.

TAVEIRA, R. A. V. Alinhamento entre a regulação sanitária e as políticas públicas de medicamentos no Brasil. Dissertação (Mestrado em Ciências Farmacêuticas) - Faculdade de Ciências da Saúde, Universidade de Brasília, Brasília, 2013. 208 p.

VEJA. Ajuda da CGU. São Paulo, 2012a. Disponível em: < http://veja.abril.com.br/blog/radaron-line/tag/dirceu-barbano/>. Acesso em: 28 nov. 2014.

. Oposiçâo de servidores. São Paulo, 2012b. Disponível em: < http://veja.abril.com.br/ blog/radar-on-line/tag/dirceu-barbano/>. Acesso em: 28 nov. 2014.

VIGEVANI, T.; MARIANO, M. P.; MENDES, R. G. Instituiçôes e conflitos comerciais no Mercosul. São Paulo em perspectiva. São Paulo, v. 16, n. 1, p. 44-53, 2002.

\section{Notas}

${ }^{1}$ A ANS tem por finalidade institucional promover a defesa do interesse público na assistência suplementar à saúde, regulando as operadoras setoriais, inclusive quanto às suas relaçôes com prestadores e consumidores (art. $3^{\circ}$ da Lei no 9.961, de 28 de janeiro de 2000).

${ }^{2} \mathrm{O}$ Sistema Nacional de Vigilância Sanitária compreende o conjunto de ações definido pelo $₫ 1^{\circ}$ do art. $6^{\circ}$ e pelos arts. 15 a 18 da Lei no 8.080 , de 19 de setembro de 1990, executado por instituiçóes da 
Administração Pública direta e indireta da União, dos Estados, do Distrito Federal e dos Municípios, que exerçam atividades de regulação, normatização, controle e fiscalização na área de vigilância sanitária (BRASIL, 1999).

${ }^{3}$ Primeiro ano de publicação do relatório de atividades.

${ }^{4}$ Período disponível do relatório da Amcham. Disponivel em: <https://www.amcham.com.br/repositorio-de-arquivos/relatorios-anvisa>.

${ }^{5} \mathrm{O}$ artigo 57 do Decreto-Lei n. 986, de 21 de outubro de 1969, estabelece que a importaçáo de alimentos, aditivos e substâncias a serem empregadas na fabricaçáo de qualquer artigo que entre em contato com alimentos será acompanhada de análise de controle "efetuada obrigatoriamente no momento de seu desembarque no país" (BRASIL, 1969).

${ }^{6}$ Folha de São Paulo: (25/01/1997, p. 13, Dinheiro); (31/01/1997, p. 4, Dinheiro); (21/02/1997, p. 7, Dinheiro); (25/02/1997, p. 8, Dinheiro).

${ }^{7}$ Folha de São Paulo: (01/10/1998, p. 5, Dinheiro).

${ }^{8}$ Licenciamento automático é o procedimento mais comum para se registrar uma importação. Ele é feito automaticamente durante a formulação da Declaração de Importação (DI), após a chegada da mercadoria no país. Para isso, o importador tem que registrar no Siscomex as informaçóes comerciais, financeiras, cambiais e fiscais da operação. Somente com a DI processada poderá ser feito o despacho aduaneiro (FIOCRUZ, 2014).

${ }^{9}$ Averbug, economista do convênio BNDES-PNUD, em seu texto "Abertura e integração comercial brasileira na década de 90", citou que medidas protecionistas são típicas de países latino-americanos frente ao deficit em conta corrente (1999, p. 58).

${ }^{10}$ Mal refeita do impacto da crise asiática, que começou em outubro de 1997 e gerou forte onda de desvalorizaçôes das moedas da região, prejudicando a balança comercial brasileira, a economia foi exposta aos efeitos desestabilizadores da crise russa em 1998 (AVEBURG, 1999).

${ }^{11}$ Os técnicos da equipe de transição tiveram aproximadamente um mês para visitar ministérios, secretarias e programas do governo FHC, com o objetivo de traçar um retrato do país que o novo presidente encontraria no dia $1^{\circ}$ de janeiro de 2003 . No dia 20 de dezembro de 2002, a MP n ${ }^{\circ} .76$, que permitiu a criação da equipe de transição, foi promulgada com a Lei no. 10.609/2002.

${ }^{12} \mathrm{O}$ "mensaláo" é o nome do principal escândalo que atingiu o governo Lula em 2005 e que consistia em um esquema de pagamento de propina a parlamentares para que votassem a favor de projetos do governo (FAUSTO, 2013).

${ }^{13}$ Folha de São Paulo: (30/03/2005, p. 2, Primeiro caderno); (21/08/2005, p. 4, Primeiro caderno).

${ }^{14}$ Sebastião (2007) relatou que, em entrevista com os atores internos, estes destacam que a existência de um regulamento técnico é um ponto forte do controle sanitário da importação, mas que a resolução era confusa e dava margem a uma segunda interpretação, em algumas situações.

${ }^{15}$ Folha de São Paulo: (08/11/2006, p. 6, Primeiro caderno); (13/02/2007, p. 4, Primeiro caderno); (13/03/2007, p. 4, Primeiro); (13/07/2007, p. 4, Primeiro caderno); (03/08/2007, p. 4, Primeiro caderno); (15/08/2007, p. 4, Primeiro caderno); (17/08/2007, p. 12, Primeiro caderno).

${ }^{16}$ C. T. S. Delphim foi responsável pela concepção e projeto do estudo, revisão bibliográfica, coleta e interpretação dos dados e resultados, redação do artigo. G. E. M. Kornis foi responsável pela concepçáo do estudo, interpretação dos resultados, redação e revisão do artigo, aprovação da versão final a ser publicada. 


\section{Abstract}

\section{Another look at sanitary surveillance of products in Brazil: the sanitary control legislation of imports in focus}

This article focuses on the regulation adopted by Brazil in relation to health inspection of imports of goods under sanitary surveillance. The study incorporated the political, technical, economic and institutional aspects involved in the sanitary control of imports. Noteworthy is also the identification of actors relevant in the formulation and implementation of standards. In this perspective, we performed singular study of all norms published between 1996 and 2013 edited from the former Health Surveillance Secretariat to the National Sanitary Surveillance Agency (Anvisa). As a result, five standards were selected for analysis as well as its subsequent amendments, featuring a qualitative exploratory study based on thematic content analysis. The examination of this material allowed to draw a trajectory of sanitary control of imports, which unfolded from the analysis of standards, allowing highlight the conditions for changes in regulations and the effects of such changes. It was observed that both the elaboration and later developments of norms were influenced by political and economic changes observed in the country and the world, suffering the determination of international organizations and intra and extrainstitutional actors, which led to restrictions in the health control products imported. The study allowed a better understanding of the practice of sanitary surveillance in the import scope.

> Keywords: sanitary legislation; National Health Surveillance Agency; import of goods; health regulation. 